\title{
EDUCAÇÃO E DESENVOLVIMENTO PARA ALCANÇAR OS OBJETIVOS DE DESENVOLVIMENTO SUSTENTÁVEL
}

\author{
Educación y desarrollo para alcanzar los objetivos de desarrollo sustentable
}

A educação é base do desenvolvimento, alguns dos caminhos para alcançar os objetivos de desenvolvimento sustentável da Agenda 2030 das Nações Unidas. Este tema norteou as atividades da IV Jornada Ibero-Americana de Pesquisas em Políticas Educacionais e Experiências Interdisciplinares na Educação (IV JORNEDUC): Desafios da educação na Agenda 2030 para o desenvolvimento sustentável, realizada de 4 a 6 de setembro de 2019, em Salvador, Bahia, e organizada pela UFBA, UNEB, UCSAL e a Associação Nova Paideia. 0 evento contou com investigadores e docentes de várias instituições e países e buscou fomentar o debate acerca das políticas e das práticas educativas, mediante o intercâmbio de ideias e a interação entre pessoas. 0 número extraordinário da Revista Nova Paideia, que agora se publica, resulta do comprometimento da organização em divulgar o conteúdo das palestras proferidas durante o evento referido e promover a sua vocação ibérica, englobando artigos escritos em português e espanhol. Os manuscritos que compõem este Número 3 da revista propõem uma perspectiva transdisciplinar enriquecedora. 0 primeiro trabalho, Educação de qualidade para todos: que qualidade?, enfatiza os conceitos educação para todos e qualidade do ensino-aprendizagem, alertando para a necessidade de uma clarificação prévia, antes da sua implementação. 0 artigo seguinte, La Agenda 2030 y los desafíos para la educación superior, aborda o ensino superior e de investigação, enfocado no desenvolvimento sustentável, nas dificuldades e soluções para alcançar o conhecimento. Apresenta-se no trabalho seguinte, o Brasil e os Desafios da Educação e dos educadores na Agenda 2030 das Nações Unidas, um panorama da situação atual do país no que diz respeito à educação em geral e aos educadores envolvidos, tendo em conta os objetivos de desenvolvimento sustentável. 0 artigo Hacia los Objetivos de la Agenda 2030 de las Naciones Unidas a través de la educación e el desarrollo articula os conceitos educação e desenvolvimento, a partir de publicações e atividades das organizações internacionais. Para concluir este número, o trabalho Profissão docente em contexto de diversidade: cartografias das pesquisas em gênero $e$ sexualidade na Bahia preocupa-se com as pesquisas sobre minorias, realçando a importância de atender a diversidade da população, para que todos os cidadãos do mundo possam alcançar o desenvolvimento e o bem estar social. Boa leitura. Fazemos votos para que este número aporte informação e conhecimento, indispensáveis para a formação holística do ser humano.
La educación es la base del desarrollo, algunas de las formas de lograr los objetivos de desarrollo sostenible de la Agenda 2030 de las Naciones Unidas. Este tema guió las actividades de la IV Conferencia Iberoamericana sobre Investigación de Políticas Educativas y Experiencias Interdisciplinarias en Educación (IV JORNEDUC): Desafíos de la Educación en la Agenda 2030 para el Desarrollo Sostenible, realizada del 4 al 6 de septiembre de 2019, en Salvador, Bahía, y organizada por UFBA, UNEB, UCSAL y la Associação Nova Paideia. Al evento asistieron investigadores y docentes de diversas instituciones y países y buscó fomentar el debate sobre políticas y prácticas educativas, a través del intercambio de ideas e interacción entre las personas. El número extraordinario de la revista Nova Paideia, que ahora se está publicando, es el resultado del compromiso de la organización de difundir el contenido de las conferencias impartidas durante el evento y promover su vocación ibérica, incluyendo los artículos escritos en portugués y español. Los manuscritos que componen este Número 3 de la revista proponen una perspectiva transdisciplinaria enriquecedora. El primer trabajo, Educação de qualidade para todos: que qualidade? enfatiza los conceptos de educación para todos y la calidad de la enseñanza y el aprendizaje, alertando sobre la necesidad de aclaraciones previas antes de su implementación. El siguiente artículo, La Agenda 2030 y Desafíos para la educación superior, aborda la educación superior y la investigación, centrándose en el desarrollo sostenible, las dificultades y las soluciones para lograr el conocimiento. El siguiente documento, o Brasil e os Desafios da Educação e dos educadores na Agenda 2030 das Nações Unidas, presenta una visión general de la situación actual del país con respecto a la educación en general y los educadores involucrados, teniendo en cuenta los objetivos de desenvolvimiento sustentable. El artículo Los objetivos de la Agenda 2030 de las Naciones Unidas a través de la Educación y el Desarrollo articula los conceptos de educación y desarrollo, a partir de publicaciones y actividades de organizaciones internacionales. Para concluir este número, el trabajo Profissão docente em contexto de diversidade: cartografias das pesquisas em gênero e sexualidade na Bahia se ocupa de la investigación sobre las minorías, destacando la importancia de abordar la diversidad de la población para que todos los ciudadanos del mundo puedan alcanzar desarrollo y bienestar social. Buena lectura. Esperamos que este número proporcione información y conocimiento, indispensables para la formación integral del ser humano.

\section{Fernanda Maria Melo Alves} Editora-Convidada 